Nemanja Rašić

Univerzitet u Beogradu

Fakultet političkih nauka
UDC: 004.738.5:37

DOI: $10.18485 /$ dh.2015.2.ch6

\title{
UPOTREBA DIGITALNIH MEDIJA U SLUŽBI OBRAZOVANJA
}

\begin{abstract}
Sažetak
Važnost digitalnih medija u obrazovanju, u savremeno doba, predstavlja veoma važnu naučnu, ali i svakodnevnu temu, nedovoljno istraženu u praksi.

Predmet istraživanja ovog rada je upotreba digitalnih medija, društvenih mreža i različitih platformi u službi poboljšanja kvaliteta učenja, kako za nastavno osoblje, tako i za studente. Cilj ovog istraživanja je analiza i obrazlaganje razloga važnosti digitalnih medija u oblasti savremenog obrazovanja, kao i objašnjenje primene istih.

Kroz ovaj rad će biti naglašena važnost detaljnog objašnjavanja, ali i dubinskog istraživanja. S obzirom da bez dubinske analize nema preduslova za detaljno razjašnjavanje određenih pojava, društvena opravdanost se ogleda kroz analizu karakteristika digitalnih medija i primene istih u obrazovanju. Ovaj rad je i naučno opravdan, s obzirom na to da predstavlja relevantan izvor informacija za buduća istraživanja iz navedene oblasti. Metode korišćene u ovom radu su metoda kvalitativno-kvantitativne eksplikacije, statistička metoda i metoda klasifikacije.

Hipoteze u ovom istraživanju se odnose na uzročno-posledičnu vezu između digitalnih medija i kvaliteta rada u obrazovanju, gde se akcenat stavlja na pretpostavku da digitalni mediji poboljšavaju kvalitet rada u obrazovanju. Takođe, pretpostavka je i da primena digitalnih medija u obrazovanju olakšava rad nastavnog osoblja i studenata.

Zaključci ovog rada odnose se na povezanost digitalnih medija sa svakodnevnim naučnim radom i radom u obrazovanju uopšte. Rezultati ovog istraživanja se nalaze u službi naučnog objašnjenja važnosti primene digitalnih medija u obrazovanju.
\end{abstract}

Ključne reči: digitalni mediji, obrazovanje, Internet, komuniciranje, mreža, računarski podržano učenje

Komuniciranje je postalo sve usložnjenije sa sve većom rasprostranjenošću Interneta. Sve do pojave istog, najbliže instant komunikaciji što su ljudi imali bila je upotreba fiksne i, kasnije, mobilne telefonije. Ipak, interakcija putem istih bila je svedena na isključivo glasovno komuniciranje, 
te je funkcija istog bila uska, a podrazumevala je visoke troškove. Sa pojavom i razvojem Interneta, brojnih programa, bloga i društvenih mreža, naročito u 21. veku, ljudska komunikacija je umnogome uznapredovala.

Sa omasovljenom upotrebom društvenih mreža i raznolikih platformi, ljudi su sve više počeli da prelaze u digitalni svet, razvijaju svoj digitalni identitet, bave se mrežnim komuniciranjem, učenjem i razmenom sadržaja. Nastavili su da obavljaju svoje svakodnevne aktivnosti, uz obavezno prisustvo nekog od uređaja koji će im omogućiti da budu u toku sa svim online dešavanjima (lap top, pametni telefon, tablet i slično).

Kada su u pitanju kvalitet obrazovanja, širenje znanja, ali i međuljudski odnosi između predavača i učenika/studenata, digitalni mediji mogu doprineti razvijanju istih. Ukoliko su upotrebljeni na pravi način, uz pravovremenu obuku nastavnog osoblja, mogu omogućiti širok aspekt kvalitetnog obrazovanja. Oni omogućavaju korišćenje rasprostranjenijih digitalnih alata za potrebe učenja, samostalno učenje, samostalno programiranje i individualnu organizaciju rada u obrazovnim ustanovama.

Stvaranjem dobro organizovane digitalne komunikacione mreže može se postići efikasnije studiranje, lakši vid nastave, ispunjavanje predispitnih obaveza, kao i mogućnost dobre povratne informacije u vezi sa problemima prilikom učenja, istraživanja i slično.

Internet omogućava da se studiranje podigne na viši nivo korišćenjem brojnih dostupnih online alata i platformi za rad u dobro organizovanom digitalnom okruženju.

Osavremenjivanjem sistema rada uvođenjem digitalnih medija u svakodnevni rad studenata i profesora postiže se bolja efikasnost i zadovoljstvo postignutim.

Digitalna pomoć pri obrazovanju može se iskoristiti i primeniti na više načina (i na taj način je objašnjena u nastavku):

- Primena Moodle-a u obrazovanju

- Primena društvenih mreža u obrazovanju

- Primena bloga u obrazovanju

- Primena drugih digitalnih alata u obrazovanju

Hard copy literatura (literatura u štampanom formatu) više nije dovoljna kako bi se nastavne jedinice prelazile dovoljno efikasno i interaktivno. Sa novim tehnologijama, primenljivim u učenju, ostavljena je velika 
mogućnost učenicima i studentima da koriste online izvore u potrazi za neophodnom literaturom. To je moguće na više načina - kupovinom online literature, kroz digitalne biblioteke, kroz Creative Commons (Creative Commons je međunarodna neprofitna organizacija koja omogućava kontinuiranu razmenu kreativnosti i znanja posredstvom besplatnih pravnih instrumenata. Creative Commons ima saradnike iz celog sveta, uključujuči i CC Srbije, čijom se aktivnošću postiže međunarodno važenje licenci i razvijanje svesti o značaju ovog poduhvata. CC licencama se pruža podrška onima koji žele da podstaknu korišćenje svojih dela davajući ih na raspolaganje pod fleksibilnim i standardizovanim uslovima, onima koji korišćenjem tih dela stvaraju nova dela, kao i ostalima koji žele da koriste sva ta dela. Vizija CC se ogleda u podržavanju pune realizacije mogućnosti Interneta) materijale. (Creative Commons Srbije, Web.)

Postoje brojne tehnologije (hologrami, 3D prikazi, simulacije, Internet arhive, itd.) koje mogu olakšati i poboljšati funkcionisanje i kvalitet učenja, bez potrebe za komplikovanim izmenama nastavnog plana i programa, kao i procesa reakreditacije predmeta. Na taj način će nastavni planovi i programi biti u toku sa dešavanjima i trendovima, a kvalitet nastave i količina prenetog znanja biti podignuta na viši nivo. Krajnji cilj ovakvog pristupa obrazovanju je osposobljavanje studenata za samostalna istraživanja, ambicioznije i inovativnije pristupe usavršavanju.

Tako se postižu efikasnost i obostrano zadovoljstvo predavača i studenata, zato što se na savremeni način pristupa obrazovanju i organizaciji rada u obrazovnoj ustanovi.

\section{Primena Moodle-a u obrazovanju}

Moodle (skraćenica od: Modular Object-Oriented Dynamic Learning Environment) je platforma za učenje osmišljena da omogući predavačima, administratorima i polaznicima određenog kursa snažan, bezbedan i integrisan sistem, radi stvaranja personalizovanog okruženja za učenje. Pruža brojne pogodnosti nastavnicima i studentima u osnovnim funkcijama nastavne delatnosti: predavanje, učenje, provera znanja, komunikacija i saradnja. (About Moodle, Web.) 
Neke od mogućnosti ove platforme su:

- organizovanje velikog broja kurseva (iz različitih oblasti, u okviru različitih fakulteta i Univerziteta)

- $\quad$ korišćenje multimedijalnih nastavnih materijala i obrazovnih sadržaja (tekstovi, audio materijali, video materijali, prezentacije, URL koji vodi ka drugim Internet stranicama, itd.)

- mnogobrojni alati omogućavaju efikasnu komunikaciju i kolaboraciju nastavnika sa studentima, kao i između studenata (organizovanje chat sobe, foruma, online konsultacija, ostavljanje privatnih i javnih poruka, itd.)

- provera znanja sa ocenjivanjem (kroz različite vrste organizovanih testova, zadataka koji mogu biti vremenski ograničeni, itd.)

- $\quad$ upravljanje i prilagodljivost sistema stalno se razvijaju i unapređujju (kroz uvođenje novih mogućnosti)

- pogodan za potpuno samostalne online kurseve ili kao dodatak kursevima lice-u-lice (Šta je Moodle, Web.)

Kroz profesionalnu i odgovornu organizaciju Moodle kursa, mogu se poboljšati uslovi rada pri obrazovnim ustanovama, ali tako i olakšati pristup informacijama, kako polaznicima kursa, tako i samim profesorima.

Polaznicima kursa je moguće postavljati dnevne, nedeljne, mesečne, semestralne zadatke, zadatke koji su vremenski ograničeni, te tako uticati na njihovu organizaciju, ali i na timski i samostalni rad. Na ovaj način se poboljšava i razvoj digitalnog identiteta studenata i načina na koji oni pristupaju upotrebi Interneta i njegovih alata i platformi. Tako polaznici određenog kursa mogu otvoriti sopstveni nalog i pohađati kurs u trenutku kada njima to najviše odgovara, uz svest o unapred određenim obavezama koje moraju ispuniti do određenog roka.

\section{Primena društvenih mreža u obrazovanju}

Standardizovani izraz za besplatne Internet servise jeste - društvene mreže. Ovo je bukvalni prevod sa engleskog jezika (social networks) i u srpskom jeziku nije sasvim pogodan, iako je ustaljen u svakodnevnom govoru. Razlog za to jeste što nisu baš svi ti sajtovi koji se upotrebljavaju mreže. Neki od njih su servisi, neki platforme, a neki aplikacije i tako dalje. 
Društvene mreže mogu doprineti obrazovanju kroz lako povezivanje, stavranje masovnih Internet zajednica na kojima se na jednom mestu mogu dobiti sve važne informacije u različitim oblicima.

Pretraživanje prema ključnim rečima je takođe jedna od lakših načina na koji učenici i studenti mogu pronaći ono neophodno na društvenim mrežama, bilo da je u pitanju informacija u vezi sa ispitnim radovima, dodatnim ili korisnim informacijama i slično. Putem Twitter-a je veoma lako informisati se o određenom proizvodu, osobi, kompaniji ili pojmu, korišćenjem hashtag-ova, odnosno, Twitter-ovog rešenja za isticanje ključnih pojmova. Pre pojave društvenih mreža ključne reči nisu igrale toliku ulogu jer nije postojalo toliko platformi i Internet stranica uopšte na kojima je tako lako i brzo bilo moguće pronaći nekoga ili nešto. Primena istih mogućnosti u obrazovanju omogućava, kako nastavnom osoblju, tako i studentima i učenicima, da lakše, podrobnije i kvalitetnije prošire svoja znanja, mogućnosti, ali i zainteresovanost za određenu oblast.

Istraživanje relevantnih zvaničnih stranica za potrebe informisanja je ključno u pretrazi Interneta. Kada je korišćenje istog u službi obrazovanja u pitanju, neophodno je naglasiti da nije svaki izvor ujedno i dobar izvor informacija. Neophodno je oslanjati se na zvanične Internet stranice, proverene zvaničnike, ljude i mesta od poverenja. Internet, kao prostor širokog spektra, pruža mogućnosti i da se stvore brojne pseudoinformacije, jer svako ko poseduje računar, može u etar „pustiti“ bilo kakvu informaciju.

Ono što je još jedna od pogodnosti upotrebe društvenih mreža, Interneta i mnogobrojnih online alata jeste saznavanje korisnih informacija u vezi sa pospešivanjem obrazovanja i studentskog standarda. To je moguće kroz konkurisanje za dobijanje određenih stipendija, obuka, praksa, učešća u projektima, sve na jednom mestu (široko umreženom, ali jednom), uz direktno konsultovanje sa administratorima određenih portala, fondacija, članova HR tima neke kompanije i slično.

Uz ozbiljnost i profesionalnost u radu, društvene mreže predstavljaju ozbiljan alat u svakodnevnom i celoživotnom obrazovanju i mogu umnogome pomoći ili zameniti direktnu komunikaciju licem u lice

U svojoj knjizi „Globalno selo“, Anđelko Milardović navodi da se pod pojmom društvene mreže misli na određeni strukturni tip funkcionisanja 
društva, u kojem učestvuju višestruki učesnici, koji se tu nalaze zarad uspostavljanja različitih tipova odnosa (prijateljskih, poslovnih, seksualnih, itd.). Ti tipovi interakcija, kako smatra Milardović, nastaju zarad ostvarivanja određenih ljudskih potreba ili interesa. (101)

\section{Primena bloga u obrazovanju}

Blog može doprineti neposrednijoj komunikaciji, deljenju materijala, kao i lakšem snalaženju prilikom korišćenja brojnih Internet materijala. Postoje različite online platforme za pravljenje bloga (WordPress, Blogger, Joomla, Weebly, Edublogs, Postagon, Squarespace, itd).

Nastavno osoblje jednostavno može obaveštavati studente o svim relevantnim informacijama. Ovakav vid komunikacije umnogome olakšava univerzitetske komunikacione potrebe nastavnog osoblja. Tamo gde treba paziti jeste količina ličnih informacija studenata koji se objavljuju na određenom blogu, koji nije zvanična Internet stranica određenog fakulteta (ili bilo koje druge obrazovne institucije).

Studenti mogu imati svoju sekciju za nedoumice i komentare. Na taj način mogu razmenjivati individualna i grupna iskustva, pomagati budućim studentima, konsultovati se sa onima koji su ranije već pohađali određeni kurs, predmet ili fakultet uopšte. Umrežavanje i globalizacija komuniciranja omogućavaju lakše širenje neophodnih informacija. Za ovakav vid informisanja nije neophodan neki veliki vid ulaganja u vidu finansijskih investicija, već samo profesionalni pristup i želja za stvaranjem organizovane zajednice.

Mogu na jednom lokalizovanom mestu pronaći detaljne informacije u vezi sa predmetom koji pohađaju i biti deo grupe koja stvara korisnu arhivu namenjenu unapređivanju znanja budućih generacija.

Komentari na blogu mogu služiti kao instant povratna informacija. Ukoliko je organizovana jedinica pritupila ozbiljno, komentari mogu „teći“ u realnom vremenskom roku, omogućavajući primanje i pružanje raznolikih korisnih informacija. Takođe, komentari mogu veoma dobro pokazati koje nastavne jedinice nisu dovoljno pokrivene, nejasne, nedovoljno obrađene ili ne podrazumevaju korišćenje dovoljno dobre ili savremene li- 
terature. Nastavno osoblje iz svega navedenog može prilagoditi svoj način predavanja, kako bi omogućila bolje i sveobuhvatno prenošenje znanja. $\mathrm{Na}$ taj način se izbegava „prepričavanje“ literature na predavanjima, korišćenje nejasne terminologije, ustaljeno deljenje nastavnih jedinica, kao i zastarelost nastavnih materijala.

Korišćenje domaćih i stranih blogova kao izvora korisnih informacija od izuzetnog su značaja. Domaći blogovi mogu pružiti veliku količinu zanimljivih, dodatnih znanja. Ipak, kao i svemu ostalom u online sferi, i online izvoru stručnih informacija trebalo bi pristupiti sa oprezom. Neophodno je koristiti proverene izvore informacija, blogove koji su se kroz iskustvo pokazali kao kvalitetni i opravdani kao reference. U suprotnom, može doći do širenje dezinformacija. Dobar primer za nepouzdane izvore informacija i namerno širenje dezinformacija je lažno proglašenje Dobrice Ćosića za dobitnika Nobelove nagrade za književnost za 2011. godinu. (Ćosić nobelovac - na lažnom sajtu, Web)

Ova vest se u trenutku objavljivanja proširila Internetom velikom brzinom i tako „povukla“ različite pouzdane izvore informacija da je objave. Zato je od izuzetne važnosti koristiti prave i stručne sagovornike, pouzdane Internet stranice, a ne samo one do kojih je najlakše doći.

Mogućnost snimanja video klipova i tutorijala koji na interaktivniji, zanimljiviji i inovativniji način objašnjavaju tematiku takođe su jedna od mogućnosti plasiranja inovativnog, originalnog i kvalitetnog sadržaja.

Upravo putem Interneta mediji sprovode svoj uticaj i grade nove nivoe sopstvenog imidža. Herman i Mekčesni smatraju da su informacijski autoputevi preovladali medijskom sferom upravo putem Interneta, pozivajući se na odluku iz 1995. godine Saveta za međunarodne telekomunikacije, prema kojoj je Internet dobio visoke ocene u borbi za prevlast na tržištu informacija. (176-177)

Burges i Grin o YouTube-u kažu da se isti doživljava kao platforma koja pruža pristup kulturi, kao i da predstavlja spoj starih i novih medijskih industrija i formi. (14)

Komuniciranje je sa pojavom različitih Internet stranica postalo dostupnije različitim ljudima, kako običnom čoveku, tako i javnim ličnostima, kompanijama, raznim organizacijama. Iste sada direktno mogu komunicirati sa svojim pratiocima i vršiti svakodnevnu interakciju sa njima. Uz 
razvoj i veću dostupnost ovih servisa, lakše dolazi do brisanja granice između običnog građanina i javne ličnosti.

Burges i Grin napominju da postojanje novih kanala komunikacije i platformi za komuniciranje otvara nove mogućnosti, naročito kada je u pitanju korist amatera koji iz objavljivanja određenog sadržaja dobijaju određenu korist, te da često upravo taj sadržaj od njih stvara javne ličnosti. (23-24)

Džozef Tjurou smatra da je digitalna konvergencija veoma zahtevna tema. Kaže i da ista postavlja pitanje o početku i kraju medijske industrije, ali i o diskutabilnosti davanja određenog imena određenoj industriji. Takođe, Tjurou ističe da dolazi do potencijalnog brisanja granica između imenovanja vrsta medija u savremeno doba, s obzirom na modernost današnjih medija, gde postoje mediji koji objedinjuju do sada dostupni sadržaj (tekst, fotografija, audio i video zapisi). (295-296)

\section{Primena drugih digitalnih alata u obrazovanju}

Osim navedenih, moguće je koristiti druge alate i platforme kako bi se obrazovanje dovelo na viši nivo. U nastavku su analizirane mogućnosti 3 takva alata - Raw, Trello i Google Drive.

Raw je koristan alat koji omogućava prikazivanje naših podataka. Dobar je za projektne aktivnosti. U pitanju je koristan alat koji omogućava raznoliku vizuelizaciju naših podataka. Podaci se unose prevlačenjem Excel fajla sa tabelarnim informacijama koje želimo da vizuelizujemo. Ono što ga izdvaja jeste:

- Omogućava dobar prikaz statističkih podataka

- Jasan i lak alat za poslovne, ali i privatne potrebe

- Dobar za osavremenjivanje aktivnosti studenata

- Dobar dizajn omogućava kvalitetan prikaz relevantnih podataka nekog istraživanja

- Dobra primena modernih tehnologija u naučnim istraživanjima

- Dobar za osavremenjivanje održavanja predavanja - omogućava predavaču da učini predavanja življim i atraktivnijim (Raw, Web) 
Raw se u obrazovanju može iskoristiti kako bi se zanimljivije predstavio željeni materijal. Samim tim, brojni tabelarni prikazi mogu delovati daleko zanimljivije i biti prijemčiviji za učenje i dalje istraživanje. Ovaj alat nije težak za savladavanje, te se upotreba istog može samostalno naučiti, ukoliko postoji interesovanje. Tako se i nastavno osoblje, ali i polaznici određenog kursa/predmeta mogu motivisati da predstave svoja istraživanja na drugačiji način. Ovaj alat je veoma prilagodljiv tipu podataka koje posedujemo, te se iz obilja mogućnosti može odabrati ona vrsta koja je neophodna za bolji rad.

Trello je alat koji omogućava dobar način radne organizacije, ali i saradnje na projektima i radovima. Ovo je Internet platforma za kolaborativni rad, koja omogućava dobar način radne organizacije. Pruža mogućnost organizacije rada po board-ovima (panelima, tablama), uz mogućnost kooperacije i integracije podataka neophodnih za dobro organizovan radni prostor. Neke od mogućnosti koje ovaj alat pruža su:

- stvaranje board-ova za rad (koji omogućavaju bolju radnu organizaciju, podelu rada, pravljenje digitalne beležnice)

- mogućnost konsultovanja i deljenja znanja (kroz pozivanje drugih ljudi koji bi želeli da podele svoje znanje iz navedene oblasti)

- razdvajanje obaveza po važnosti, obimu, rokovima, itd. (kroz moguću organizaciju po bojama, vremenu, važnosti i slično) (Trello, Web)

Primena Trello-a u obrazovanju je takva da se može koristiti kao organizator radnog prostora za učenje. Na „dnevni“, „nedeljni“, „mesečni“ ili bilo koji drugi (onako kako ga samostalno definišemo) red se mogu staviti različite vrste obaveza, online materijala, tekstova, nedoumica i slično. Takođe, moguće je i samostalno vođenje napretka iz određene oblasti kroz vreme.

Google Drive je jednostavnija, skromnija, online alternativa Office paketu sa pogodnim alatima za online deljenje i konsultaciju radova na licu mesta između studenata i profesora. U Google Drive-u se mogu pronaći:

- Docs

- Sheets

- Slides 
- Forms

- Drawings

- Maps (Google Drive, Web)

Google Drive se u obrazovanju može koristiti kao aplternativa Office paketu. Ukoliko obrazovna ustanova nije nabavila legalnu licencu za korišćenje softvera, ova kombinacija online dostupnih alata omogućiće praktičnu i opšte dostupnu obradu teksta. Upravo su najvažnije i najčešće korišćene opcije Office paketa uključene u ovu kombinaciju alata. Ipak, mogućnosti su mu daleko ispod mogućnosti celog Office paketa, ali postoji mogućnost korišćenja istog u obrazovanju. Ovaj alat pruža mogućnost vođenja digitalnih i opšte dostupnih spiskova, zapisnika, pravljenja prezentacija, baza podataka, vođenja evidencije o ocenama ili drugim tabelarnim nastavnim ili vannastavnim aktivnostima. Još jedna od pozitivnih karakteristika jeste dobra umreženost, te se može lako povezati između više različitih korisnika, koji u isto vreme mogu zajednički raditi na jednom projektu. Ovu mogućnost je Office paket omogućio i pravilno razradio tek od verzije Office 2016, te je ranijim korisnicima Google Drive-a ova opcija dostupna i poznata od samog početka.

\section{Zaključna razmatranja}

Kroz prikazane mogućnosti osavremenjivanja rada u obrazovanju objašnjeno je kako se obrazovni sistem može osavremeniti i učiniti zabavnijim i prijemčivijim. Digitalni mediji umnogome mogu pospešiti kvalitet nastave i obrazovanja uopšte kroz:

- bolju organizaciju rada, zato što pružaju bolju umreženost, veći opseg komunikacionih, organizacionih i informacionih mogućnosti

- mogućnost stalnog kontrolisanja ocena i predispitnih obaveza, kroz jedinstvene sisteme predodređene samo za tu upotrebu

- dobru komunikaciju, različitim kanalima (putem društvenih mreža, privatnih i zvaničnih e-mail adresa, foruma, blogova, komentara i slično)

- mogućnost kreativnijeg izražavanja ideja, koristeći neke od ranije navedenih alata, pomoću kojih je jasnost prikazivanja sadrža- 
ja na prvom mestu, uz mogućnost vizuelnog izdvajanja na novi, drugačiji način

- zabavnijeg pristupa učenju, uz postizanje dobrih rezultata, stvaranja mogućnosti studentima da se na kreativan, sebi svojstven način posvete učenju i iskažu individualni pristup, ali i kritičko mišljenje, koje je ponekad zaboravljeno

Mogući problemi na koje se može naići prilikom korišćenja nekog od navedenih alata/sajtova/platformi:

- obučavanje nastavnog osoblja, gde se može naići na manjak interesovanja samog nastavnog osoblja ili na manjak inicijative i organizacije da bi se ovakav projekat sproveo u delo, zarad poboljšanja kvaliteta rada i prenošenja znanja

- nepostojanje volje za napretkom, usred stava da su trenutni uslovi, alati i materijali dovoljni za prenošenje znanja

- nepostojanje spremnosti za upotrebu digitalnih alata usled tradicionalnih vidova učenja i radne organizacije, te se hard copy materijali često uzimaju kao jedini prilikom radne organizacije

- manjak podrške radnog okruženja, gde fakultetska zajednica nije voljna da učestvuje u napredovanju usled „nasleđenih" tradicionalnih načina rada, bez želje za unapređivanjem i osavremenjivanjem pristupa u teorijskom, ali i praktičnom smislu

- hakovanje, kao jedna od najnegativnijih strana digitalnog prostora, gde je moguće doći do određenih informacija ilegalnim putem, uz manipulisanje istim

Kada su u pitanju navedene hipoteze ovog rada, one su analizirane i detaljnije opisane kroz ceo rad. Naime, u ovom istraživanju glavna hipoteza se odnosi na uzročno-posledičnu vezu između odnosa digitalnih medija i kvaliteta rada u obrazovanju. Naime, pretpostavljeno je da digitalni mediji podižu kvalitet rada u obrazovanju. Ova pretpostavka je potvrđena u potpunosti i objašnjena kroz različite stavke ovog rada. Uz korišćenje digitalnih medija moguće je podići nivo obrazovanja na viši nivo.

Takođe, pretpostavka je i da primena digitalnih medija u obrazovanju olakšava rad nastavnog osoblja i studenata. Ova pretpostavka je tako- 
đe potvrđena i objašnjena kroz rad. Naime, uz primenu digitalnih alata i mogućnosti, osavremenjivanja svakodnevnog rada i inovativnog pristupa obrazovanju i usavršavanju, nastavno osoblje, ali i učenici/studenti mogu naučiti nove načine i pristupe učenju, kao što su online kursevi, digitalno vođenje evidencije, nadgradnja istraživačkog potencijala, digitalne biblioteke, digitalni sertifikati i slično.

Korišćenjem digitalnih medija u obrazovanju pospešujemo istraživački potencijal nadolazećih akademskih generacija i novih članova naučne zajednice. Ukoliko se korišćenje istih započne na nižim nivoima obrazovanja, veće su šanse da će se povećati i unaprediti istraživački opseg, količina primljenog znanja, kao i kvalitet kritičkog rasuđivanja i individualnog obrazovanja.

\section{Literatura}

Burgess, Jean and Joshua Green, YouTube Online Video and Participatory Culture: How YouTube Matters, Cambridge, Polity Press, 2009. Print

Herman, Edvard S. i Robert V. Mekčesni, Globalni mediji: Globalni mediji, Internet i digitalna revolucija, Beograd, Clio, 2004. Print

Milardović, Anđelko, Globalno selo: Analitika. Društvene mreže kao aspekt cyber kulture, Zagreb, Centar za politikološka istraživanja, 2010. Print

Tjurou, Džozef, Mediji danas II: Industrija Interneta i video-igara, Beograd, Clio, 2013. Print

Creative Commons Srbije, O licencama, 2015. Web. 15. okt. 2015.

http://creativecommons.org.rs/?page_id=38\#o1a1

Google, Google Drive, 2015. Web. 15. nov. 2015.

https://www.google.com/drive/

Moodle, About Moodle, 10.nov 2015. Web 15. nov. 2015.

https://docs.moodle.org/29/en/About_Moodle

Moodle, Šta je Moodle, 2015. Web. 15. okt. 2015.

http://moodle.agrif.bg.ac.rs/mod/resource/view.php?inpopup=true\&id=4982

Raw, How It Works, 2015. Web. 15. nov. 2015.

http://raw.densitydesign.org/

RTV, Ćosić nobelovac - na lažnom sajtu, 6. okt. 2011. Web. 10. okt 2015.

http://www.rtv.rs/sr_lat/kultura/cosic-nobelovac-na-laznom-sajtu_276984.html

11. Trello, About Trello, 2015. Web. 15. nov. 2015.

https://trello.com/about 


\title{
Nemanja Rašić \\ University of Belgrade \\ Faculty of Political Sciences
}

\section{"THE USAGE OF DIGITAL MEDIA IN EDUCATION"}

\begin{abstract}
Summary
The importance of digital media in education, in modern times, is a very important scientific, but also everyday topic, insufficiently explored in practice. The subject of this work is the use of digital media, social networks and different platforms in the service of improving the quality of learning, both for teachers and students. The aim of this research is to analyze and explain the importance of digital media in the field of modern education, as well as an explanation of their application. This study will emphasize the importance of a detailed explanation, and in-depth research. Given that without an indepth analysis there are no prerequisites for detailed clarification of certain phenomena, social justification is reflected in the analysis of the characteristics of digital media

and their application in education. This study is scientifically justified, given the fact that it represents a relevant source of information for future research in the respective field. The methods used in this paper are methods of qualitative and quantitative explication, statistical methods and classification methods. The hypothesis of this study are related to the cause-and-effect relationship between digital media and the quality of work in education, where the emphasis is on the assumption that digital media enhance the quality of work in education. Also, the assumption is that the application of digital media in education facilitates the work of teachers and students. The conclusions of this study are related to the connection of digital media with daily scientific work, and work in education in general. The results of this research are in the service of scientific explanations of the importance of application of digital media in education.
\end{abstract}

Key words: digital media, education, Internet, communication, network, technology enhanced learning 